\title{
Predicting the mechanical properties of ordinary concrete and nano-silica concrete using micromechanical methods
}

\author{
M LEZGY-NAZARGAH*D, S A EMAMIAN, E AGHASIZADEH and M KHANI \\ Faculty of Civil Engineering, Hakim Sabzevari University, Sabzevar, P.O. Box 9617976487, Iran \\ e-mail: m.lezgy@hsu.ac.ir
}

MS received 7 February 2018; revised 4 May 2018; accepted 12 June 2018; published online 30 October 2018

\begin{abstract}
By combining several materials with specific mechanical properties, new materials with unknown mechanical properties are obtained. Various experiments are required to determine the mechanical properties of the produced composite materials. Since conducting experiment processes is costly and time-consuming, comprehensive studies have been conducted in recent years to solve the problem. Fortunately, it is possible to easily predict the mechanical properties of composite materials without the need to construct them, by inspecting their constituent's properties using micromechanical methods. Although various micromechanical methods have been presented so far, few of them yielded precise predictions of the properties of composite materials. Therefore, selecting a method suitable to predict the properties of composite materials is of much importance. In this study, some micromechanical approaches, including Hirsch, Hansen, Bache, Cavento, Mori-Tanaka, Eshelby, self-consistent, effective interface and double-inclusion models, were employed for the estimation of elasticity modulus and Poisson's ratio of ordinary and nanomaterial concretes. The results obtained from the micromechanical methods were compared to those obtained from experimental tests. The obtained numerical results showed that Bache's model is the most accurate micromechanics model for predicting the elastic mechanical properties of ordinary and nanomaterial concretes.
\end{abstract}

Keywords. Micromechanics; concrete; nano-silica; homogenization.

\section{Introduction}

Composite materials, though homogenous in large or macroscale, have heterogeneous structure in small or micro-scale. They are actually composed of a combination of several materials with specific mechanical properties. For example, in manufacturing concrete, different materials (phases) such as aggregate and cement paste are combined so that the final material will have the expected properties like compressive strength and ductility. Accurate experiments are needed to determine the properties of multi-phase materials. Properties of composite materials depend on the volume percent and features of primary constituents. Due to the fact that the volume percent of phases of composite materials varies, determining the properties of composite materials and selecting the best choice to use involve trial and error. Conducting multiple experiments and investigating the obtained results are very costly and time-consuming. As a result, attempt has been made by researchers to find theoretical solutions to predict the properties of composite materials. The theoretical solutions used to predict the properties of composite materials are now known as micromechanical methods and are given attention by many researchers.

*For correspondence
Studies on micromechanics emerged about a century ago in 1907 by Volterra [1]. He started his research by studying the elastic stress and strain fields surrounding concavities and defects of materials. Based on the principles of continuum mechanics of materials, Volterra developed theories that relate the reaction of materials to parameters inside the materials. By studying the non-local behaviour, Volterra found that stress at one spot does not merely depend on strain at that spot but it also depends on strain at surrounding spots. Mindlin [2] developed a micromechanical linear elasticity theory in 1964, which allows stresses to be dependent on both strains and a small transformation tensor. Related research such as Eringen [3] led to the development of micro-polar and couple-stress theories in 1968. These theories consider material transformation to include a series of translational and rotational degrees of freedom. Integrating the theories of continuum mechanics with micro-polar and couple-stress theories led to more developments in micromechanical methods. Among these studies, the studies of Bardenhagen and Trianfyllidis [4] and Chang and Gao [5] can be referred to.

Regarding the conducted studies, Cowin and Nunziato [6] developed a theory of composite material elasticity by taking cavities into consideration. Another prominent theory is doublet mechanics suggested by Ferrari et al [7]. This 
theory considers composite materials as an arrangement of points or particles interacting according to micromechanical rules. Other studies by Budianski and O'Connell [8] and Kachanov [9] have also investigated composite materials with scattered cracks. In some studies, statistical and probabilistic methods were used to develop models with random changes in mechanical properties, among which the study by Starzewski-Ostoja and Wang [10] can be referred to. Mura [11] collected the results of all studies on micromechanics and invented the eigen-strain technique. Elastic modelling of defects, cracks and other heterogeneities became feasible using the eigen-strain technique of Mura. Shokriyeh and Parsayi [12] studied micro-buckling of composite materials under compressive loading using three types of volume elements: hexagon, square and circle. The results of this study showed that when fibrereinforced composite materials are compressively loaded in line with fibres, they are destroyed before fibre buckling, due to the effect of fibre buckling or the effect of transverse fracture in resin. In compressive loading, there are two buckling states for fibres: the first one is shear buckling and the second one is lateral buckling. In this study, the type of volume element suitable for micro-modelling was investigated. The results of the study of Shokriyeh and Parsayi [12] showed that in fibre buckling in micro-scale, the resin that surrounds the fibres does not undergo buckling. Norris [13] studied the mechanical properties of two-phase composites using a discrete element method. Dai et al [14] were able to predict the effective elasticity modulus of multiphase hybrid composites by combining Mori-Tanaka and self-consistent models. Shokriyeh and Elahi [15] presented a new model for estimating the elasticity modulus of polymer concrete using micromechanical models. The model of these researchers is based on Mori-Tanaka's model. Since the Mori-Tanaka model is weak in the estimation of elasticity modulus of composite materials with high impurity volume percent, an attempt was made by Shokriyeh and Elahi [15] to eliminate this drawback by taking into consideration the effect of impurity in the matrix phases. Mean-field homogenization techniques are commonly based on the results of Eshelby [16]. Eshelby surveyed issues such as determining impurity strain in infinite space of matrix and calculating stress in elliptical impurities of matrix. Eshelby's computations, which account for the interior and exterior of impurities, are now the basis of many micromechanical theories. Based on isofield assumptions, Lezgy-Nazargah [17] derived explicit formulations for computing the effective coupled thermoelectro-elastic material properties of Macro Fibre Composites in the linear regime. Lezgy-Nazargah and Eskandari-Naddaf [18] developed a novel extended iso-field micromechanical model for estimating the effective coupled thermo-electro-elastic material coefficients of threephase piezoelectric structural fibre composites.

Concrete is one of the most applicable materials in civil engineering. Accurate prediction of the mechanical properties of concrete materials is of great interest for civil engineers. Beycioğlu et al [19] introduced a rule based on Fuzzy Logic model for predicting the flexural strengths and compressive strengths of blended cements at elevated temperatures. For prediction of the concrete properties, Chen et al [20] collected sets of mixtures that include fly ash, slag and silica. These researchers developed a new database platform, with the stepwise multiple linear regression and artificial neural networks programs for identifying correlations between the concrete properties and the dosage and/or quality of materials. Najjar et al [21] used a database to develop Fuzzy Logic models as predictive tools for the grout flow ability and mechanical properties of two-stage concrete mixtures. They evaluated the performance of the developed models using statistical parameters and error analyses. By combining two different techniques, Neural Networks and Principal Component Analysis, Boukhatem et al [22] successfully predicted the slump and compressive strength of concrete with mineral additives such as blast furnace slag, fly ash and silica fume. Chu et al [23] proposed prediction models for estimating the hydration properties of concrete, such as the compressive strength, the splitting tensile strength, the elastic modulus and the autogenous shrinkage.

Although studies on micromechanics methods emerged about a century ago, applicable research works on these methods for predicting the mechanical properties of concrete materials are limited. Indeed, finding a micromechanics method suitable to predict the properties of concrete materials is of much importance for civil engineers. The purpose of this research was to predict the mechanical properties of ordinary concrete and nano-silica concrete using different micromechanical methods. Hirsch, Hansen, Cavento, Batch, self-consistent, Eshelby, MoriTanaka, effective interface and double-inclusion models were investigated in this research. The elasticity modulus and Poisson's ratio of different samples of ordinary concrete and nano-silica concrete made up of various mixtures were calculated using the mentioned micromechanical methods. The estimated results obtained from the micromechanical methods were compared to experimental results. Finally, in order to adopt a solution suitable for precise prediction of mechanical properties of concrete samples, a discussion is carried out on the results estimated by the different micromechanical methods. The effect of different parameters on the accuracy of various micromechanical methods was also investigated.

\section{Micromechanical methods}

Different micromechanical equations were employed for the prediction of the mechanical properties of the concrete material as follows.

Hirsch model [24]: 


$$
\frac{1}{E}=(1-x)\left[\frac{C_{2}}{E_{2}}+\frac{C_{1}}{E_{1}}\right]+x\left[\frac{1}{C_{2} E_{2}+C_{1} E_{1}}\right]
$$

where $E$ is the effective elasticity modulus of concrete. $E_{1}$ and $E_{2}$ are the elasticity modulus of matrix (cement paste) and impurity (aggregate), respectively. Volume percent of matrix and aggregate are represented by $C_{1}$ and $C_{2}$, respectively; $x$ is a number between 0 and 1 that determines the relative share of parallel (equivalent-constant-strain state) and series (equivalent-constant-stress state) models in the calculation of effective elasticity modulus.

Hansen model [25]:

$$
E=\left(\frac{C_{1} E_{1}+\left(1+C_{2}\right) E_{2}}{\left(1+C_{2}\right) E_{1}+C_{1} E_{2}}\right) E_{1} .
$$

Cavento model [26]:

$$
\frac{1}{E}=\frac{1-\sqrt{C_{2}}}{E_{1}}+\frac{1}{\left(\frac{1-\sqrt{C_{2}}}{\sqrt{C_{2}}}\right) E_{1}+E_{2}}
$$

Batch model [27]:

$$
E=E_{1}^{C_{1}} E_{2}^{C_{2}}
$$

Mori-Tanaka method [28]:

$$
\boldsymbol{D}=\left(C_{1} \boldsymbol{D}_{1}+C_{2} \boldsymbol{D}_{2} \mathbf{T}^{p}\right)\left(C_{1} \boldsymbol{I}+C_{2} \boldsymbol{T}^{p}\right)^{-1}
$$

where $\boldsymbol{D}$ is the tensor of effective elasticity constants of the composite material (concrete); $\boldsymbol{D}_{1}$ and $\boldsymbol{D}_{2}$ are the tensors of matrix (cement paste) and impurity (aggregate) elasticity constants; $\boldsymbol{I}$ is the unit tensor (that is, a tensor whose entries or elements of its main diagonal are 1 and other entries are 0 ) and $\boldsymbol{T}^{p}$ is the tensor of centralized strain of impurities calculated as follows:

$$
\boldsymbol{T}^{p}=\left[\boldsymbol{I}+\boldsymbol{S}^{p}\left(\boldsymbol{D}_{1}\right)^{-1}\left(\boldsymbol{D}_{2}-\boldsymbol{D}_{1}\right)\right]^{-1}
$$

where $\boldsymbol{S}^{p}$ is Eshelby's tensor, which depends on the form of impurities. For instance, for a composite material with isotropic matrix and spherical impurities, entries of Eshelby's tensor are calculated using the following equations:

$$
\begin{aligned}
& S_{1111}=S_{2222}=S_{3333}=\frac{7-5 v}{15(1-v)} \\
& S_{1122}=S_{2233}=S_{3311}=S_{1133}=S_{2211}=S_{3322}=\frac{5 v-1}{15(1-v)} \\
& S_{1212}=S_{2323}=S_{3131}=\frac{4-5 v}{15(1-v)}
\end{aligned}
$$

where $v$ is Poisson's ratio of the matrix phase.

Eshelby's method [16, 29]:

$$
K=K_{1}+\frac{C_{2}\left(K_{2}-K_{1}\right)\left(3 K_{1}+4 G_{1}\right)}{3 K_{2}+4 G_{1}}
$$

$$
G=G_{1}+\frac{5 C_{2} G_{1}\left(G_{2}-G_{1}\right)\left(3 K_{1}+4 G_{1}\right)}{3 K_{1}\left(3 G_{1}+2 G_{2}\right)+4 G_{1}\left(2 G_{1}+3 G_{2}\right)}
$$

where $K$ and $G$, respectively, are the effective bulk and shear modulus of the composite material. Subscripts 1 and 2 denote the matrix (cement paste) and impurity (aggregate), respectively.

Self-consistent method [30]:

$$
\begin{array}{r}
K=K_{1}+\frac{C_{2}\left(K_{2}-K_{1}\right)(3 K+4 G)}{3 K_{2}+4 G} \\
G=G_{1}+\frac{5 C_{2} G\left(G_{2}-G_{1}\right)(3 K+4 G)}{3 K\left(3 G+2 G_{2}\right)+4 G\left(2 G+3 G_{2}\right)}
\end{array}
$$

Effective interface method [31]:

$$
\begin{aligned}
\boldsymbol{D}= & \boldsymbol{D}_{1}+\left[\left(C_{2}+C_{i}\right)\left(\boldsymbol{D}_{i}-\boldsymbol{D}_{1}\right) \mathbf{T}^{p i}\right. \\
& \left.+C_{2}\left(\boldsymbol{D}_{2}-\boldsymbol{D}_{i}\right) \mathbf{T}^{p}\right] \\
& \times\left[C_{1} \boldsymbol{I}+\left(C_{2}+C_{i}\right) \boldsymbol{T}^{p i}\right]^{-1}
\end{aligned}
$$

where

$$
\begin{gathered}
\boldsymbol{T}^{p}=\boldsymbol{I}-\boldsymbol{S}^{p}\left[\boldsymbol{S}^{p}+\left(\boldsymbol{D}_{2}-\boldsymbol{D}_{1}\right)^{-1} \boldsymbol{D}_{1}\right]^{-1} \\
\boldsymbol{T}^{p i}=\boldsymbol{I}-\boldsymbol{S}^{p} \times\left\{\frac{C_{2}}{C_{i}+C_{2}}\left[\boldsymbol{S}^{p}+\left(\boldsymbol{D}_{2}-\boldsymbol{D}_{1}\right)^{-1} \boldsymbol{D}_{1}\right]^{-1}\right. \\
\left.+\frac{C_{i}}{C_{i}+C_{2}}\left[\boldsymbol{S}^{p}+\left(\boldsymbol{D}_{i}-\boldsymbol{D}_{1}\right)^{-1} \boldsymbol{D}_{1}\right]^{-1}\right\}
\end{gathered}
$$

and $C_{i}$ is the volume percent of the interface between two phases of matrix and impurity. $\boldsymbol{D}_{\boldsymbol{i}}$ denotes the tensor of elasticity constants of the interface of the two phases.

Double-inclusion method [32]:

$$
\boldsymbol{D}=\boldsymbol{D}_{1}+C_{2}\left(\boldsymbol{D}_{2}-\boldsymbol{D}_{1}\right) A
$$

where

$$
\begin{gathered}
\boldsymbol{A}=\left\{(1-\lambda)\left[\boldsymbol{A}^{1}\right]^{-1}+\lambda\left[\boldsymbol{A}^{u}\right]^{-1}\right\}^{-1} \\
\boldsymbol{A}^{1}=\left\{\boldsymbol{I}+\boldsymbol{S}^{P}\left[\left(\boldsymbol{D}_{1}\right)^{-1} \boldsymbol{D}_{2}-\boldsymbol{I}\right]^{-1}\right\}^{-1} \\
\boldsymbol{A}^{u}=\boldsymbol{I}+\boldsymbol{S}^{P}\left[\left(\boldsymbol{D}_{2}\right)^{-1} \boldsymbol{D}_{1}-\boldsymbol{I}\right]^{-1} \\
\lambda=\frac{1}{2} C_{2}\left(1+C_{2}\right) .
\end{gathered}
$$

\section{Numerical results}

Here, elasticity modulus and Poisson's ratio of ordinary concrete and nano-silica concrete materials were determined using the micromechanical methods presented 
previously. Based on the mathematical formulation introduced in the previous section, a computer code is developed in MATLAB programming software for each micromechanics model. Results obtained from these different micromechanical methods are compared to experimental results and the accuracy of each method is evaluated.

\subsection{Estimating the mechanical properties of ordinary concrete}

Concrete is one of the most common materials used in civil engineering applications. In this section, the mechanical properties of some ordinary concrete samples with different mix designs have been estimated using different micromechanics models. Details of the mix design of these different concrete samples are shown in table 1. As shown in this table, four types of aggregate, including steel, glass, sand and rubble, and three types of cement paste with water to cement ratios $(W / C) 0.286,0.294$ and 0.315 were used. In preparing concrete samples, the volume percent of aggregate was considered as 10\%, 20\% and 30\%. Although the volume fraction of aggregate in the concrete is generally higher than $30 \%$, for the purpose of comparison with data available in literature such values are assumed. In table 1, Poisson's ratios as well as modulus of elasticity of cement paste and aggregate are also given for each concrete sample. These values are obtained by Huang et al [33] via experimental tests.

It is well known that concrete has several phases, including aggregate, cement paste, air bubbles and microcracks. Although it is necessary to account for all these mentioned phases in the determination of the effective elasticity modulus of the concrete, due to complexities, only two phases, that is, aggregate and cement paste, are being used in calculations. Indeed, the cement paste is assumed to be the matrix phase while the aggregates are assumed to be the impurity phase. The results obtained from estimation of elasticity modulus of ordinary concrete using Hirsch, Hansen, Cavento and Batch micromechanical methods are shown in tables 2 and 3. It is worth noting here that these estimated results are obtained from a MATLAB code whose algorithm is based on the mathematical formulations given in section 2 . In tables 2 and 3 , the estimated micromechanics results have been compared with experimental results of Huang et al [33]. It can be deduced from table 2 that the results of Hirsch model are more accurate for mixtures with aggregate volume percent less than $20 \%$. Table 2 also reveals the fact that the accuracy of Hirsch and Hansen models in the prediction of the elasticity

Table 1. Mechanical properties and specifications of mixtures of the ordinary concrete samples [33].

\begin{tabular}{|c|c|c|c|c|c|c|c|c|}
\hline & $W / C$ & $\begin{array}{c}\text { Type of } \\
\text { aggregate }\end{array}$ & $\begin{array}{l}\text { Volume percent } \\
\text { of cement paste }\end{array}$ & $\begin{array}{l}\text { Volume } \\
\text { percent of } \\
\text { aggregate }\end{array}$ & $\begin{array}{l}\text { Poisson's } \\
\text { ratio of } \\
\text { aggregate }\end{array}$ & $\begin{array}{l}\text { Elasticity modulus } \\
\text { of aggregate }(\mathrm{GPa})\end{array}$ & $\begin{array}{l}\text { Poisson's ratio } \\
\text { of cement paste }\end{array}$ & $\begin{array}{l}\text { Elasticity modulus } \\
\text { of cement paste } \\
(\mathrm{GPa})\end{array}$ \\
\hline 1 & 0.286 & Steel & 90 & 10 & 0.33 & 205.8 & 0.228 & 32.11 \\
\hline 2 & 0.286 & Steel & 80 & 20 & 0.33 & 205.8 & 0.228 & 32.11 \\
\hline 3 & 0.286 & Steel & 70 & 30 & 0.33 & 205.8 & 0.228 & 32.11 \\
\hline 4 & 0.286 & Glass & 90 & 10 & 0.28 & 72.2 & 0.228 & 32.11 \\
\hline 5 & 0.286 & Glass & 80 & 20 & 0.28 & 72.2 & 0.228 & 32.11 \\
\hline 6 & 0.286 & Rubble & 90 & 10 & 0.23 & 38.0 & 0.228 & 32.11 \\
\hline 7 & 0.286 & Rubble & 80 & 20 & 0.23 & 38.0 & 0.228 & 32.11 \\
\hline 8 & 0.286 & Rubble & 70 & 30 & 0.23 & 38.0 & 0.228 & 32.11 \\
\hline 9 & 0.294 & Steel & 90 & 10 & 0.33 & 205.8 & 0.217 & 28.46 \\
\hline 10 & 0.294 & Steel & 80 & 20 & 0.33 & 205.8 & 0.217 & 28.46 \\
\hline 11 & 0.294 & Glass & 90 & 10 & 0.28 & 72.2 & 0.217 & 28.46 \\
\hline 12 & 0.294 & Glass & 80 & 20 & 0.28 & 72.2 & 0.217 & 28.46 \\
\hline 13 & 0.294 & Glass & 70 & 30 & 0.28 & 72.2 & 0.217 & 28.46 \\
\hline 14 & 0.294 & Rubble & 90 & 10 & 0.23 & 38.0 & 0.217 & 28.46 \\
\hline 15 & 0.294 & Rubble & 80 & 20 & 0.23 & 38.0 & 0.217 & 28.46 \\
\hline 16 & 0.294 & Rubble & 70 & 30 & 0.23 & 38.0 & 0.217 & 28.46 \\
\hline 17 & 0.315 & Steel & 90 & 10 & 0.33 & 205.8 & 0.208 & 23.83 \\
\hline 18 & 0.315 & Steel & 80 & 20 & 0.33 & 205.8 & 0.208 & 23.83 \\
\hline 19 & 0.315 & Steel & 70 & 30 & 0.33 & 205.8 & 0.208 & 23.83 \\
\hline 20 & 0.315 & Glass & 90 & 10 & 0.28 & 72.2 & 0.208 & 23.83 \\
\hline 21 & 0.315 & Glass & 80 & 20 & 0.28 & 72.2 & 0.208 & 23.83 \\
\hline 22 & 0.315 & Glass & 70 & 30 & 0.28 & 72.2 & 0.208 & 23.83 \\
\hline 23 & 0.315 & Sand & 90 & 10 & 0.23 & 54.0 & 0.208 & 23.83 \\
\hline 24 & 0.315 & Sand & 80 & 20 & 0.23 & 54.0 & 0.208 & 23.83 \\
\hline 25 & 0.315 & Sand & 70 & 30 & 0.23 & 54.0 & 0.208 & 23.83 \\
\hline 26 & 0.315 & Rubble & 90 & 10 & 0.23 & 38.0 & 0.208 & 23.83 \\
\hline
\end{tabular}


Table 2. Estimation of elasticity modulus of ordinary concrete using Hirsch, Hansen, Cavento and Batch models (results are stated in $\mathrm{GPa})$.

\begin{tabular}{|c|c|c|c|c|c|c|c|c|c|c|c|}
\hline $\begin{array}{l}\text { Sample } \\
\text { no. }\end{array}$ & $\begin{array}{l}\text { Hirsch model } \\
\qquad(x=0.3)\end{array}$ & $\begin{array}{c}\text { Error } \\
(\%)\end{array}$ & $\begin{array}{l}\text { Hirsch model } \\
\qquad(x=0.5)\end{array}$ & $\begin{array}{l}\text { Error } \\
(\%)\end{array}$ & $\begin{array}{c}\text { Hansen } \\
\text { model }\end{array}$ & $\begin{array}{c}\text { Error } \\
(\%)\end{array}$ & $\begin{array}{c}\text { Cavento } \\
\text { model }\end{array}$ & $\begin{array}{l}\text { Error } \\
(\%)\end{array}$ & $\begin{array}{l}\text { Batch } \\
\text { model }\end{array}$ & $\begin{array}{c}\text { Error } \\
(\%)\end{array}$ & $\begin{array}{l}\text { Experimental } \\
\text { results [33] }\end{array}$ \\
\hline 1 & 38.426 & 0.78 & 41.046 & 7.65 & 37.167 & 2.52 & 40.115 & 5.21 & 38.665 & 1.40 & 38.13 \\
\hline 2 & 44.231 & 1.40 & 48.965 & 9.15 & 43.090 & 3.95 & 46.972 & 4.71 & 46.558 & 3.79 & 44.86 \\
\hline 3 & 50.396 & 8.12 & 56.928 & 3.79 & 50.119 & 8.62 & 54.378 & 0.86 & 56.063 & 2.21 & 54.85 \\
\hline 4 & 34.607 & 0.52 & 35.026 & 0.68 & 34.676 & 0.33 & 35.266 & 1.37 & 34.820 & 0.09 & 34.79 \\
\hline 5 & 37.236 & 1.74 & 38.019 & 3.88 & 37.457 & 2.34 & 38.236 & 4.47 & 37.758 & 3.17 & 36.60 \\
\hline 6 & 32.640 & 1.57 & 32.657 & 1.52 & 32.654 & 1.53 & 32.676 & 1.46 & 32.655 & 1.52 & 33.16 \\
\hline 7 & 33.182 & 1.15 & 33.212 & 1.07 & 33.207 & 1.08 & 33.236 & 0.99 & 33.210 & 1.07 & 33.57 \\
\hline 8 & 33.736 & 8.20 & 33.776 & 8.09 & 33.770 & 8.11 & 33.800 & 8.03 & 33.774 & 8.10 & 36.75 \\
\hline 9 & 34.517 & 0.72 & 37.204 & 8.56 & 33.121 & 3.35 & 36.014 & 5.09 & 34.686 & 1.21 & 34.27 \\
\hline 10 & 39.920 & 4.97 & 44.718 & 6.45 & 38.615 & 8.08 & 42.421 & 0.98 & 42.274 & 0.63 & 42.01 \\
\hline 11 & 31.014 & 3.65 & 31.513 & 2.10 & 31.045 & 3.55 & 31.742 & 1.39 & 31.236 & 2.96 & 32.19 \\
\hline 12 & 33.694 & 6.12 & 34.628 & 3.51 & 33.877 & 5.61 & 34.799 & 3.04 & 34.284 & 4.47 & 35.89 \\
\hline 13 & 36.575 & 1.78 & 37.878 & 1.72 & 36.992 & 0.67 & 37.963 & 1.94 & 37.629 & 1.05 & 37.24 \\
\hline 14 & 29.258 & 1.09 & 29.303 & 0.94 & 29.288 & 0.98 & 29.349 & 0.78 & 29.294 & 0.96 & 29.58 \\
\hline 15 & 30.084 & 5.34 & 30.164 & 5.08 & 30.142 & 5.15 & 30.221 & 4.90 & 30.153 & 5.12 & 31.78 \\
\hline 16 & 30.939 & 8.65 & 31.047 & 8.33 & 31.021 & 8.41 & 31.102 & 8.17 & 31.038 & 8.36 & 33.87 \\
\hline 17 & 29.484 & 0.98 & 32.233 & 10.39 & 27.931 & 4.34 & 30.693 & 5.12 & 29.563 & 1.24 & 29.20 \\
\hline 18 & 34.291 & 0.86 & 39.102 & 13.05 & 32.806 & 5.16 & 36.432 & 5.33 & 36.676 & 6.03 & 34.59 \\
\hline 19 & 39.357 & 0.81 & 45.888 & 15.65 & 38.694 & 2.48 & 42.708 & 7.63 & 45.500 & 14.67 & 39.59 \\
\hline 20 & 26.404 & 3.42 & 27.013 & 1.19 & 26.357 & 3.59 & 27.191 & 0.54 & 26.623 & 2.62 & 27.34 \\
\hline 21 & 29.075 & 8.05 & 30.216 & 4.44 & 29.169 & 7.75 & 30.271 & 4.26 & 29.744 & 5.93 & 31.62 \\
\hline 22 & 31.953 & 7.89 & 33.55 & 3.28 & 32.313 & 6.85 & 33.485 & 3.47 & 33.231 & 4.20 & 34.69 \\
\hline 23 & 25.701 & 0.99 & 26.018 & 2.23 & 25.571 & 1.19 & 26.198 & 2.94 & 25.861 & 1.62 & 25.45 \\
\hline 24 & 27.671 & 5.34 & 28.264 & 7.59 & 27.835 & 5.96 & 28.425 & 8.21 & 28.065 & 6.84 & 26.27 \\
\hline 25 & 29.784 & 5.13 & 30.607 & 8.04 & 30.101 & 6.25 & 30.720 & 8.44 & 30.458 & 7.51 & 28.33 \\
\hline
\end{tabular}

modulus of ordinary concrete is almost equal. According to the results of Batch model in table 2, it can be stated that the elasticity modulus of mixtures having less aggregate percent is more in agreement with experimental results. In the present study, the concrete material is modelled as a composite formed by a matrix (cement paste) with embedded inclusions (aggregate). Since the size of inclusions (i.e., aggregate) in comparison with other impurities is relatively high, the mechanical properties of interface between the cement paste and aggregates affects the mechanical properties of concrete. It is well known that the structure of cement paste in the vicinity of the aggregates differs from that of bulk cement paste. The phase in which the presence of the aggregates affects the properties of cement paste is taken as the Interfacial Transition Zone (ITZ). Therefore, concrete is a three-phase material consisting of cement paste matrix, discrete inclusions of aggregate and an ITZ between the matrix and inclusions $[34,35]$. With increasing percentage aggregate volume, the effects of elastic properties of ITZ phase on the mechanical properties of concrete increase. Since the considered micromechanics models used in the present study are not able to consider the effects of ITZ phase in the formulation, the discrepancy between the present and experimental results increases with increasing percentage aggregate volume. It appears that more refined micromechanics models are needed for the accurate prediction of mechanical properties of concrete materials with high percentage aggregate volume. This issue will be addressed by the authors in another paper.

The modulus of elasticity of the concrete samples estimated by Mori-Tanaka, self-consistent, effective interface and double-inclusion micromechanics models is presented in table 3. In estimating the elasticity modulus of concrete using Mori-Tanaka model, three different forms were considered for the impurity shape (here aggregate): spherical, elliptical with ratio 1:2 and elliptical with ratio 1:3. As can be observed, the estimated elasticity moduli by assuming spherical shape for aggregates are smaller than the estimated elasticity moduli by assuming elliptical shape for aggregates. This difference is more obvious in mixtures in which the difference between the elasticity modulus of aggregate and matrix is high. As shown in table 3, it can be concluded that the Mori-Tanaka method by assuming elliptical shapes with ratio 1:3 for the impurity (aggregates) leads to more accurate results in predicting the elasticity modulus of concrete. Since the shape of aggregates in reality is closer to an ellipse than a sphere, the results of Mori-Tanaka method by assuming elliptical shape for aggregates are closer to the experimental results. In 


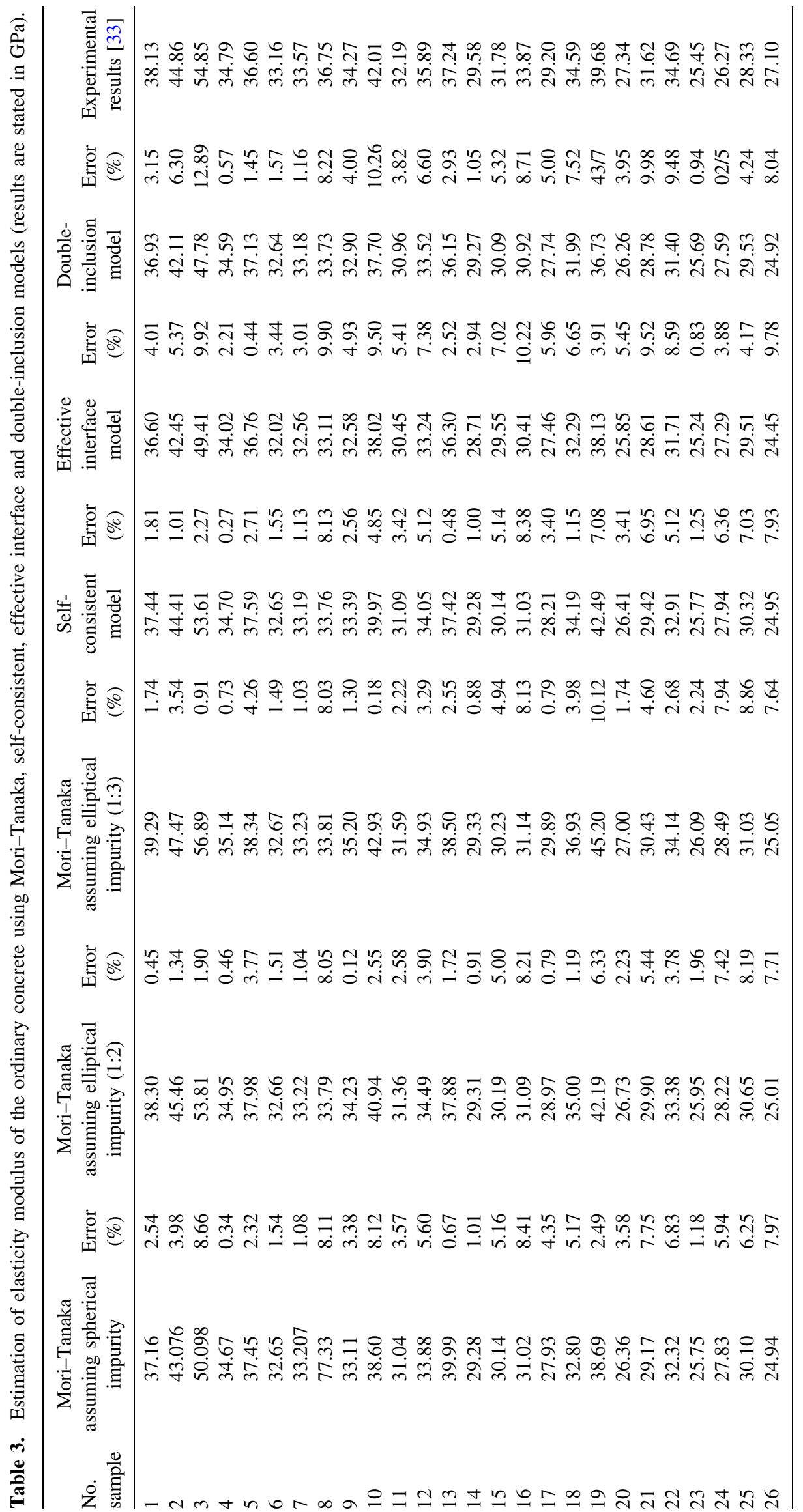


Table 4. Results obtained from estimation of Poisson's ratio of ordinary concrete using different micromechanical methods.

\begin{tabular}{|c|c|c|c|c|c|c|}
\hline $\begin{array}{l}\text { Sample } \\
\text { no. }\end{array}$ & $\begin{array}{l}\text { Self- } \\
\text { consistent }\end{array}$ & $\begin{array}{l}\text { Mori-Tanaka assuming } \\
\text { spherical impurity }\end{array}$ & $\begin{array}{l}\text { Mori-Tanaka assuming } \\
\text { elliptical impurity }(1: 2)\end{array}$ & $\begin{array}{l}\text { Mori-Tanaka assuming } \\
\text { elliptical impurity (1:3) }\end{array}$ & $\begin{array}{l}\text { Effective } \\
\text { interface }\end{array}$ & $\begin{array}{l}\text { Double } \\
\text { inclusion }\end{array}$ \\
\hline 1 & 0.23 & 0.23 & 0.23 & 0.24 & 0.23 & 0.23 \\
\hline 2 & 0.24 & 0.23 & 0.24 & 0.24 & 0.23 & 0.23 \\
\hline 3 & 0.24 & 0.24 & 0.25 & 0.25 & 0.24 & $24 / 0$ \\
\hline 4 & 0.23 & 0.23 & 0.23 & 0.23 & 0.23 & 0.23 \\
\hline 5 & 0.24 & 0.24 & 0.24 & 0.24 & 0.24 & 0.24 \\
\hline 6 & 0.23 & 0.23 & 0.23 & 0.23 & 0.23 & 0.23 \\
\hline 7 & 0.23 & 0.23 & 0.23 & 0.23 & 0.23 & 0.23 \\
\hline 8 & 0.23 & 0.23 & 0.23 & 0.23 & 0.23 & 0.23 \\
\hline 9 & 0.22 & 0.22 & 0.22 & 0.23 & 0.22 & 0.22 \\
\hline 10 & 0.23 & 0.23 & 0.23 & 0.24 & 0.22 & 0.22 \\
\hline 11 & 0.22 & 0.22 & 0.22 & 0.22 & 0.22 & 0.22 \\
\hline 12 & 0.23 & 0.23 & 0.23 & 0.23 & 0.23 & 0.23 \\
\hline 13 & 0.23 & 0.23 & 0.24 & 0.24 & 0.23 & 0.23 \\
\hline 14 & 0.22 & 0.22 & 0.22 & 0.22 & 0.22 & 0.22 \\
\hline 15 & 0.22 & 0.22 & 0.22 & 0.22 & 0.22 & 0.22 \\
\hline 16 & 0.22 & 0.22 & 0.22 & 0.22 & 0.22 & 0.22 \\
\hline 17 & 0.21 & 0.21 & 0.22 & 0.22 & 0.21 & 0.21 \\
\hline 18 & 0.22 & 0.22 & 0.22 & 0.23 & 0.22 & 0.21 \\
\hline 19 & 0.23 & 0.22 & 0.23 & 0.24 & 0.22 & 0.22 \\
\hline 20 & 0.21 & 0.21 & 0.22 & 0.22 & 0.21 & 0.21 \\
\hline 21 & 0.22 & 0.22 & 0.22 & 0.22 & 0.22 & 0.22 \\
\hline 22 & 0.23 & 0.22 & 0.23 & 0.23 & 0.22 & 0.22 \\
\hline 23 & 0.21 & 0.21 & 0.21 & 0.21 & 0.21 & 0.21 \\
\hline 24 & 0.21 & 0.21 & 0.21 & 0.21 & 0.21 & 0.21 \\
\hline 25 & 0.21 & 0.21 & 0.21 & 0.22 & 0.21 & 0.21 \\
\hline 26 & 0.21 & 0.21 & 0.21 & 0.22 & 0.21 & 0.21 \\
\hline
\end{tabular}

predicting the elasticity modulus of concrete using the effective interface micromechanics model, the volume percent of the interface of the two phases, that is, aggregate and cement paste, is considered as $1 \%$. In other words, $1 \%$ air bubble is considered in the concrete. Comparison of the results of tables 2 and 3 shows that the Batch model with mean error of $2.67 \%$ has the least error in estimating the elasticity modulus of the concrete samples.

Poisson's ratio determination is another application of the micromechanical methods. In table 4, Poisson coefficients of concrete samples with different mix designs are calculated using some of the micromechanical models (Mori-Tanaka, self-consistent, effective interface and double inclusion). As shown, different micromechanical models lead to almost equal results in predicting Poisson's ratio of the ordinary concrete material.

\subsection{Estimating the mechanical properties of nano- silica concrete}

In recent years, nano-silica particles have been widely used for increasing the compressive strength of the ordinary concrete. Therefore, studying the effect of nano-silica particles on strength and elasticity modulus of the concrete material is of much importance. In this example, the attempt was to calculate the elasticity modulus and Poisson's ratio of nano-silica concretes using the micromechanical models. With this aim, some nano-silica concrete samples with different types of mixtures are considered. Mechanical characteristics and specifications of four different types of mixtures used in the preparation of nanosilica concrete samples are shown in table 5. In the micromechanics calculations, the concrete material is assumed as the matrix while the added nano-silica is considered as the inclusion phase. For each micromechanics model described in section 2, a computer code is developed in MATLAB. The results obtained from different micromechanical models have been compared to experimental results of Saloma et al [36].

The effective elasticity modulus of nano-silica concrete estimated using different micromechanical methods is presented in table 6. Poisson's ratio of nano-silica concrete samples is also calculated using micromechanical models and the obtained results are shown in table 7 . In the estimation of elasticity modulus of nano-silica concrete samples using the Hirsch equation, it is assumed that $x=0.3$. The uptrend of elasticity modulus of the concrete on increasing nano-silica particles can be explicitly observed in table 6. As shown, the results of the micromechanical methods have an excellent agreement to experimental results. Batch and Mori-Tanaka (assuming elliptical 
Table 5. Mechanical properties and mix design of the nano-silica concrete samples [36].

\begin{tabular}{lccccrc}
\hline Sample & $\begin{array}{c}\text { Elasticity modulus } \\
\text { of phase 1 (ordinary } \\
\text { no. }\end{array}$ & $\begin{array}{c}\text { Poisson's ratio of } \\
\text { phase 1 (ordinary } \\
\text { concrete) }\end{array}$ & $\begin{array}{c}\text { Elasticity modulus of } \\
\text { phase 2 (nano-silica } \\
\text { particles) }\end{array}$ & $\begin{array}{c}\text { Poisson's ratio of } \\
\text { phase 2 (nano-silica } \\
\text { particles) }\end{array}$ & $\begin{array}{c}\text { Volume percent } \\
\text { of nano-silica } \\
\text { particles }\end{array}$ & $\begin{array}{c}\text { percent of } \\
\text { ordinary } \\
\text { concrete }\end{array}$ \\
\hline 1 & 39.7 & 0.3 & 88.7 & 0.23 & 2.5 & 5.0 \\
2 & 39.7 & 0.3 & 88.7 & 0.23 & 97.5 \\
3 & 39.7 & 0.3 & 88.7 & 0.23 & 9.5 & 9.5 \\
4 & 39.7 & 0.3 & 88.7 & 0.23 & 90.0 \\
\hline
\end{tabular}

Table 6. Estimation of elasticity modulus of nano-silica concrete using different micromechanical methods (results are stated in GPa).

\begin{tabular}{|c|c|c|c|c|c|c|c|c|}
\hline Micromechanical model & $\begin{array}{c}\text { Sample } \\
1\end{array}$ & $\begin{array}{c}\text { Sample } \\
2\end{array}$ & $\begin{array}{l}\text { Sample } \\
3\end{array}$ & $\begin{array}{l}\text { Sample } \\
4\end{array}$ & $\begin{array}{c}\text { Error }(\%) \text { of } \\
\text { Sample } 1\end{array}$ & $\begin{array}{l}\text { Error }(\%) \text { of } \\
\text { Sample } 2\end{array}$ & $\begin{array}{c}\text { Error }(\%) \text { of } \\
\text { Sample } 3\end{array}$ & $\begin{array}{c}\text { Error }(\%) \text { of } \\
\text { Sample } 4\end{array}$ \\
\hline Hirsch & 40.45 & 41.22 & 41.98 & 42.76 & 0.92 & 0.23 & 0.89 & 0.80 \\
\hline Hansen & 40.46 & 41.24 & 42.04 & 42.85 & 0.89 & 0.16 & 0.76 & 0.60 \\
\hline Cavento & 40.75 & 41.72 & 42.65 & 43.57 & 0.19 & 0.99 & 0.69 & 1.06 \\
\hline Batch & 40.50 & 41.33 & 42.17 & 43.02 & 0.79 & 0.04 & 0.45 & 0.20 \\
\hline Self-consistent & 40.46 & 41.27 & 42.10 & 42.95 & 0.90 & 0.11 & 0.62 & 0.38 \\
\hline Eshelby & 39.80 & 39.91 & 40.02 & 40.12 & 2.50 & 3.38 & 5.52 & 6.92 \\
\hline $\begin{array}{l}\text { Mori-Tanaka assuming } \\
\text { spherical impurity }\end{array}$ & 40.47 & 41.27 & 42.08 & 42.90 & 0.88 & 0.10 & 0.66 & 0.46 \\
\hline $\begin{array}{l}\text { Mori-Tanaka assuming } \\
\text { elliptical impurity }(1: 2)\end{array}$ & 40.56 & 41.43 & 42.32 & 43.22 & 0.59 & 0.44 & 0.11 & 0.52 \\
\hline $\begin{array}{l}\text { Mori-Tanaka assuming } \\
\text { elliptical impurity }(1: 3)\end{array}$ & 40.62 & 41.55 & 42.49 & 43.45 & 0.59 & 0.44 & 0.11 & 0.52 \\
\hline Effective interface & 40.47 & 41.27 & 42.08 & 42.90 & 0.88 & 0.10 & 0.66 & 0.49 \\
\hline Double inclusion & 40.47 & 41.24 & 42.02 & 42.80 & 0.88 & 0.17 & 0.80 & 0.72 \\
\hline Experimental results [36] & 40.83 & 41.31 & 42.36 & 43.11 & - & - & - & - \\
\hline
\end{tabular}

Table 7. Results obtained from estimation of Poisson's ratio of nano-silica concrete using different micromechanical methods.

\begin{tabular}{lccccccc}
\hline & \multicolumn{5}{c}{ Micromechanics model } \\
\cline { 2 - 8 } & $\begin{array}{c}\text { Self- } \\
\text { consistent } \\
\text { model }\end{array}$ & $\begin{array}{c}\text { Eshelby } \\
\text { model }\end{array}$ & $\begin{array}{c}\text { Mori-Tanaka model } \\
\text { assuming spherical } \\
\text { impurity }\end{array}$ & $\begin{array}{c}\text { Mori-Tanaka model } \\
\text { assuming elliptical } \\
\text { impurity (1:2) }\end{array}$ & $\begin{array}{c}\text { Mori-Tanaka model } \\
\text { assuming elliptical } \\
\text { impurity (1:3) }\end{array}$ & $\begin{array}{c}\text { Effective } \\
\text { interface } \\
\text { model }\end{array}$ & $\begin{array}{c}\text { Double- } \\
\text { inclusion } \\
\text { model }\end{array}$ \\
\hline 1 & 0.3 & 0.3 & 0.3 & 0.3 & 0.3 & 0.3 & 0.3 \\
2 & 0.3 & 0.3 & 0.3 & 0.3 & 0.3 & 0.3 \\
3 & 0.3 & 0.3 & 0.3 & 0.3 & 0.3 & 0.3 \\
4 & 0.3 & 0.31 & 0.3 & 0.3 & & 0.3 \\
\hline
\end{tabular}

impurity) methods having, respectively, $0.37 \%$ and $0.41 \%$ mean discrepancy have the least error in estimating the elasticity modulus of nano-silica concrete. In the present case study, the concrete material is assumed to be the matrix and the added nano-silica is considered to be the inclusion phase. Since the size of nano-silica particles is very small, the mechanical properties of ITZ do not affect the mechanical properties of resulting nano-silica concrete. In case of ordinary concrete, cement paste is assumed to be the matrix phase while the aggregates are considered to be the inclusion phase. As stated in the previous example, the effects of elastic properties of ITZ phase should be considered in micromechanical formulations of ordinary concrete. As the effects of ITZ phase are neglected in the present study, the accuracy of employed two-phase micromechanical models in the prediction of mechanical properties of nano-silica concrete is more than that of ordinary concrete.

\section{Conclusion}

In this research, the elasticity modulus and Poisson's ratio of ordinary concrete and nano-silica concrete was calculated using micromechanical methods. Various methods such as Hansen, Cavento, Batch, Hirsch, Mori-Tanaka, 
effective interface, Eshelby and double inclusion were used for the prediction of the mechanical properties of the concrete material. The results obtained from the micromechanical models were validated by comparing them to experimental results available in open literature.

Investigation of the results of the estimated elasticity modulus of concrete using micromechanical methods showed that the accuracy of these methods has an inverse relationship with the volume percent of aggregates. On increasing the volume percent of aggregates in the concrete mixture, the accuracy of all micromechanical methods is decreased. Numerical results obtained from the Batch model have the highest agreement with the experimental results.

Numerical results obtained from micromechanical formulations show that addition of nano-silica particles into concrete paste has significant effect on elasticity modulus of concrete, such that on increasing the volume percent of nano-silica particles, the elasticity modulus of concrete is significantly increased. Batch and Mori-Tanaka (assuming elliptical impurity) methods have the highest accuracy in the estimation of the elasticity modulus of nano-silica concrete. Unlike elasticity modulus, the effective Poisson's ratio of the nano-silica concrete is independent of the volume percent of nano particles and it is almost equal to Poisson's ratio of the ordinary concrete material.

\section{References}

[1] Volterra V 1907 Sur l'equilibre des corps elastiques multiplement connexes. Ann. Ec. Norm. (Paris) 24(3): 401-517

[2] Mindlin R D 1964 Microstructure in linear elasticity. Arch. Ration. Mech. Anal. 16: 51-78

[3] Eringen A C 1968 Theory of micropolar elasticity. New York: Academic Press, pp. 662-729

[4] Bardenhagen S and Trianfyllidis N 1994 Derivation of higher order gradient continuum theories in 2,3-D nonlinear elasticity from periodic lattice models. J. Mech. Phys. Solids 42: 111-139

[5] Chang C S and Gao J 1995 Second-gradient constitutive theory for granular material with random packing structure. Int. J. Solids Struct. 32: 2279-2293

[6] Cowin S C and Nunziato J W 1983 Linear elastic materials with voids. J. Elast. 13: 125-147

[7] Ferrari M, Granik V T, Imam A and Nadeau J 1997 Advances in doublet mechanics. Berlin: Springer

[8] Budiansky B and O'Connell R J 1976 Elastic moduli of a cracked solid. Int. J. Solids Struct. 12: 81-97

[9] Kachanov M 1994 Elastic solids with many cracks and related problems. Adv. Appl. Mech. 30: 259-445

[10] Ostoja-Starzewski M and Wang C 1990 Linear elasticity of planar Delaunay networks part ii: Voigt and Reuss bounds, and modification for centroids. Acta Mech. 84: 47-61

[11] Mura T 1987 Micromechanics of defects in solids. Dordrecht: Martinus Nijhoff
[12] Shokriyeh M and Parsayi A 2009 Studying the volume model of micro-buckling. In: Proceedings of the 2nd National Conference on Production and Manufacturing Engineering, Islamic Azad University of Najaf Abad

[13] Norris A N 1985 A differential scheme for the effective moduli of composites. Mech. Mater. 4: 1-16

[14] Dai L H, Huang Z P and Wang R A 1998 Generalized selfconsistent Mori-Tanaka scheme for prediction of the effective elastic moduli of hybrid multiphase particulate composites. Polym. Compos. 19: 506-513

[15] Shokriyeh M and Elahi M 2011 A new model to estimate Young's model for polymer concrete using micromechanical equations. Modarres Mech. Eng. J. 12(2): 153-162

[16] Eshelby J D 1957 The determination of the elastic field of an ellipsoidal inclusion and related problems. Proc. R. Soc. Lond. Ser. A A241: 376-396

[17] Lezgy-Nazargah M 2015 A micromechanics model for effective coupled thermo-electro-elastic properties of Macro Fiber Composites with interdigitated electrodes. J. Mech. 31(2): 183-199

[18] Lezgy-Nazargah M and Eskandari-Naddaf H 2017 Effective coupled thermo-electro-mechanical properties of piezoelectric structural fiber composites: a micromechanical approach. J. Intell. Mater. Syst. Struct. 29(4): 496-513

[19] Beycioğlu A, Gültekin A, Aruntaş H Y, Gencel O, Dobiszewska M and Brostow W 2017 Mechanical properties of blended cements at elevated temperatures predicted using a fuzzy logic model. Comput. Concr. 20(2): 247-255

[20] Chen B, Mao Q, Gao J and Hu Z 2015 Concrete properties prediction based on database. Comput. Concr. 16(3): 343-356

[21] Najjar M F, Nehdi M L, Azabi T M and Soliman A M 2017 Fuzzy inference systems based prediction of engineering properties of two-stage concrete. Comput. Concr. 19(2): 133-142

[22] Boukhatem B, Kenai S, Hamou A T, Ziou D and Ghrici M 2012 Predicting concrete properties using neural networks (NN) with principal component analysis (PCA) technique. Comput. Concr. 10(6): 557-573

[23] Chu I, Amin M N and Kim J K 2013 Prediction model for the hydration properties of concrete. Comput. Concr. 12(4): 377-399

[24] Hirsch T J 1962 Modulus of elasticity of concrete affected by elastic moduli of cement paste matrix and aggregate. ACI J. Proc. 59(3): 427-451

[25] Hansen T C 1965 Influence of aggregate and voids on modulus of elasticity of concrete, cement mortar and cement paste. ACI J. Proc. 62(2): 193-216

[26] Counto V J 1964 The effect of the elastic modulus of the aggregate on the elastic modulus, creep and creep recovery of concrete. Mag. Concr. Res. 16(48): 129-138

[27] Baalbaki W, Aitcin P C and Ballivy G 1992 On predicting modulus of elasticity in high-strength concrete. ACI Mater. J. 89(5): 517-520

[28] Mori $\mathrm{T}$ and Tanaka 1973 Average stress in matrix and average elastic energy of materials with misfitting inclusions. Acta Metall. 21: 571-574

[29] Eshelby J D 1959 The elastic field outside an ellipsoidal inclusion. Proc. R. Soc. Lond. Ser. A 252: 561-569

[30] Hill R 1965 A self-consistent mechanics of composite materials. J. Mech. Phys. Solids 13(4): 213-222 
[31] Dunn M L and Ledbetter H 1995 Elastic moduli of composites reinforced by multiphase particles. J. Appl. Mech. 62(4): 1023-1028

[32] Duplan F, Abou-Chakra A, Turatsinze A, Escadeillas G, Brule S and Masse F 2014 Prediction of modulus of elasticity based on micromechanics theory and application to low-strength mortars. Constr. Build. Mater. 50: 437-447

[33] Huang R, Yeih W and Sue I C 1995 Aggregate effect on elastic moduli of cement-based composite materials. J. Mar. Sci. Technol. 3(1): 5-10
[34] Hashina Z and Monteiro P J M 2002 An inverse method to determine the elastic properties of the interphase between the aggregate and the cement paste. Cem. Concr. Res. 32: 1291-1300

[35] Nadeau J C 2003 A multiscale model for effective moduli of concrete incorporating ITZ water-cement ratio gradients, aggregate size distributions, and entrapped voids. Cem. Concr. Res. 33: 103-113

[36] Saloma A, Nasution A, Imran I and Abdullah M 2013 Experimental investigation on nanomaterial concrete. Int. J. Civ. Environ. Eng. 13: 15-20 